\title{
NIETZSCHE E OS TRÁGICOS GREGOS: UMA INTRODUÇÃO AO ESTUDO DAS FONTES
}

\section{NIETZSCHE AND THE GREEK TRAGIC AUTHORS: AN INTRODUCTION TO THE STUDY OF SOURCES}

\author{
Luís Rubira \\ Universidade Federal de Pelotas, Pelotas, RS, Brasil
}

Resumo: Partindo da obra Nietzsches persönliche Bibliothek (A Biblioteca pessoal de Nietzsche), ainda sem edição no Brasil, o presente texto busca mostrar as edições das tragédias gregas de Ésquilo, Sófocles e Eurípedes, adquiridas e investigadas por Nietzsche ao longo de seu percurso intelectual, de modo a fornecer novas possibilidades de investigação tanto na esfera das letras quanto da filosofia, no que tange à pesquisa Nietzsche hoje.

Palavras-chave: Tragédia grega, Biblioteca de Nietzsche, edições investigadas

Abstract: Starting with the work Nietəsches persönliche Bibliothek (Nietəsche's personal library), not yet published in Brazil, this paper aims to show the Greek tragedies editions of Aeschylus, Sophocles and Euripides, acquired and investigated by Nietzsche throughout his intellectual journey, for provide new possibilities of research in the sphere of the literature and philosophy regarding the research on Nietzsche nowadays.

Keywords: Greek tragedy, Nietzsche' library, greek tragedies editions.

A fortuna crítica em relação à obra $O$ nascimento da tragédia a partir do espirito da música, com a qual Nietzsche inaugura sua entrada na filosofia em 1871, é bastante extensa, a começar pelas reflexões de ordem filológica que esta obra sofre a partir de 1872, tal como a de Ulrich WilamowitzMoellendorf ${ }^{8}$. É, ademais, o próprio filósofo quem, quinze anos depois, numa "tentativa de autocrítica", tenta penetrar no conteúdo de sua primeira obra e, embora a caracterize como "um livro problemático", ressalta que ela possuía em seu núcleo "uma questão de primeira ordem e máxima atração" (GT/NT, Prefácio, \$1), algo que o leva, inclusive, a alterar o título do livro para $O$ nascimento da tragédia ou helenismo e pessimismo. Nietzsche, nós sabemos, ainda volta a refletir sobre seu livro no apagar das luzes de seu pensamento, ou seja, em sua autobiografia intelectual, Ecce homo, de 1888.

Aventurar-se, portanto, nas investigações sobre o Nascimento da tragédia implica em enfrentar não somente esta "fortuna crítica" deixada pelos contemporâneos do filósofo e por ele próprio, mas investigar o conjunto de textos produzidos a partir do colapso psíquico que Nietzsche sofre em janeiro

${ }^{8}$ Cf. MACHADO, Roberto. Nietzsche e a polêmica sobre o Nascimento da tragédia. Rio de Janeiro: Editora Zahar, 2005. 
de 1889, e, em especial, os textos de intérpretes, comentadores e especialistas da obra do filósofo - textos estes que se encontram em diversos idiomas, na forma de artigos, dissertações de mestrado, teses de doutorado, capítulos de

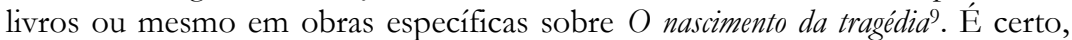
portanto, que em meio às centenas de estudos sobre o "livro problemático" com o qual Nietzsche se lança para pensar o significado das tragédias gregas na cultura helênica, produzidos, sobretudo, no século XX, pouco resta para a exploração de novas teses ou abordagens originais, às quais venham a contribuir com algo novo no universo dos estudos nietzschianos.

Uma senda de pesquisa aberta no alvorecer do século XXI, todavia, pode oferecer ainda muito caminho para ser explorado não somente em relação ao Nascimento da tragédia, mas ao conjunto das obras de Nietzsche. Trata-se do "estudo das fontes", que um dos herdeiros da chamada Escola "Colli-Montinari"10, Giuliano Campioni, vem desenvolvendo na Itália, mais especificamente no Centro Interuniversitario "Colli - Montinari" di studi su Friedrich Nietzsche e la cultura europea. Entre os diversos trabalhos realizados por Giuliano Campioni e sua equipe encontra-se um livro seminal intitulado Nietzsches persönliche Bibliothek, publicada no ano de 2003, e ainda sem edição no Brasil. Trata-se de um levantamento praticamente exaustivo das obras que Nietzsche possuía em sua biblioteca pessoal, bem como do recenseamento de muitas outras que ele leu ao longo de seu percurso intelectual. Façamos, pois, um recorte metodológico, de modo a nos debruçarmos, ainda que de modo introdutório, na reflexão sobre as fontes que Nietzsche mesmo utilizou no que diz respeito às suas leituras dos trágicos gregos.

Como sabemos, três são os trágicos gregos que o jovem Nietzsche explora em $O$ nascimento da tragédia. Segundo a tese nietzschiana, nas tragédias de Ésquilo e Sófocles, Dioniso ocupa o lugar principal da cena, enquanto que nas tragédias de Eurípedes o próprio coro dionisíaco já não tem mais sua força originária, o que representaria a decadência da tragédia, sobretudo por ele ter abandonado o elemento trágico-dionisíaco pelo racional-socrático: Eurípedes era "apenas máscara: a divindade, que falava por sua boca, não era Dionísio, tampouco Apolo, porém um demônio de recentíssimo nascimento, chamado Sócrates" (GT/NT, \$12). O modo como Nietzsche constrói esta tese poderia

\footnotetext{
9 Para um contato inicial com este manancial da fortuna crítica indicamos a leitura de três importantes revistas na esfera da pesquisa Nietzsche: Nietzsche-Studien (criada em 1972, atualmente com mais de 40 tomos); Nietzscheforschung (existente desde 1994), e os Cadernos Nietzsche (publicados semestralmente a partir de 1996, já com mais de trinta números editados).

${ }^{10}$ Giorgio Colli e Mazzimo Montinari são os responsáveis pela edição crítica das obras completas de Nietzsche em alemão, a partir da segunda metade do século XX.
} 
ter alguma relação com as edições que ele investigou? Ora, embora esta questão exceda o presente artigo, importa-nos, aqui, apenas mostrar as fontes dos trágicos gregos que Nietzsche não somente possuía, mas que leu exaustivamente, sublinhando, fazendo comentários nas margens dos livros, tal como se pode constatar em fac-simile presentes na obra Nietzsches persönliche Bibliothek ou nas obras micro-filmadas da Biblioteca Nietzsche que se encontram, por exemplo, nos arquivos da Anna Amalia Bibliothek, em Weimar.

Quais foram, portanto, as edições de Ésquilo, Sófocles e Eurípedes escolhidas por Nietzsche para suas investigações? Foram elas editadas por quais tradutores e estudiosos? E, sobretudo, quais tragédias, de fato, ele leu?

Em Nietzssches persönliche Bibliothek, Giuliano Campioni, Paolo D'Iorio, Maria Cristina Fornari, Francesco Fronterotta e Andrea Orsucci, num trabalho que levou décadas para ser elaborado, aportam diversas informações sobre cada obra, tal como, por exemplo, o ano em que Nietzsche a investigou ou mesmo a adquiriu. Como nosso foco de abordagem não é somente o período das leituras que ele realiza dos trágicos gregos até o momento de finalização de O nascimento da tragédia, mas inclui sua "tentativa de autocrítica" de 1886 e ainda sua abordagem da mesma obra realizada em 1888 em Ecce homo, nosso intento é mostrar o conjunto destas edições que acompanharam Nietzsche de seus escritos iniciais até os finais sobre a tragédia grega.

$$
* * *
$$

As obras de Ésquilo que Nietzsche elegeu para suas investigações abrangem edições realizadas de 1823 até 1874, publicadas em Leipzig (Lipsiae), com exceção de uma obra editada em Gießen (Gissae). Comportando os textos em grego, muitas das edições possuem estudos críticos ou prefácios em latim, realizadas por helenistas e filólogos alemães. São elas:

Aischylos. Tragoediae. Ad optimorum librorum fidem recensuit, integram lectionis varitatem notasque adiecit Augustus Wellauer. Lipsiae: F. C. G. Vogel, 1823. [Vol. I: Prometheum; Septem contra Thebes et Supplices continens].

Idem. Lipsiae: F. C. G. Vogel, 1824. [Vol. II: Agamêmnon; Choephoros; Eumenidas et Persas, itemque indices continens].

Aischylos. Prometheus. Griechisch mit metrischer Übersetzung und prüfenden und erklärenden Anmerkungen von J. A. Hartung. Leipzig: W. Engelmann, 1852.

Aischylos. Erinyen oder Rachegeister. Griechisch mit metrischer Übersetzung und prüfenden und erklärenden Anmerkungen von J. A. Hartung. Leipzig: W. Engelmann, 1853. 
Aischylos. Tragoediae von Aeschylus. Recognovit et praefatus est Guilielmus Dindorfius. Editio quarta correctior. Lipsiae: B. G. Teubner, 1855.

Aischylos. Agamemnon. Mit erläuternden Anmerkungen herausgegeben Von Robert Enger. Leipzig: B. G. Teubner, 1855.

Aischylos. Aeschyli Tragoediae. Recognovit et praefatus est Guilielmus Dindorfius. Editio quarta correctior. Lipsiae: B. G. Teubner, 1860.

Aischylos. Choephori. Recensuit, adnotationem criticam et exegeticam adjecit Henricus Weil, in Facultate Litterarum Vesontina Professor. Gissae: J. Ricker, 1860.

Aischylos. Die Oresteia. Agamemnon. Choephoren. Eumeniden. Deutsche Nachdichtung und Erklärung von Oswald Marbach. Leipzig: C. G. Naumann, $1874 .{ }^{11}$

Nietzsche investigou, portanto, mais de uma edição do mesmo texto estabelecido por diferentes estudiosos das tragédias gregas, tal como é o caso, por exemplo, da obra Prometeu e Orestéia. Dentre os estudiosos, cujos nomes surgem, na maior parte das vezes, em latim ou abreviados, estão os helenistas e filólogos Augustus Wellauer (August Wellauer, 1798-1831), Guilielmus Dindorfius (Karl Wilhelm Dindorf, 1802-1883), J. A. Hartung (Johann Adolf Hartung, 1801-1867), Robert Enger (Robert Enger, 1813-1873), Henricus Weil (Henri Weil, 1818-1909) e Oswald Marbach (Gotthard Oswald Marbach, 18101890), cada qual sendo autor de diversas outras obras na esfera dos estudos helênicos.

Em relação aos textos de Sófocles, as edições que Nietzsche investigava recobrem quase o mesmo período: 1823 a 1871, publicadas, também, por diversas casas editoriais alemãs:

Sophokles. Sophokles. Übersetzt von Christian Grafen zu Stolberg. Hamburg: Perthes und Besser, 1823. [Ester Band: Elektra; Oedipus in Theben; Oedipus in Kolonos].

Sophokles. Sophokles. Übersetzt von Christian Grafen zu Stolberg. Hamburg: Perthes und Besser, 1823. [Zweiter Band: Antigone; Die Trachinerinnen; Aias; Philoktetes].

Sophokles. Antigone. Griechisch mit metrischer Übersetzung und prüfenden und erklärenden Anmerkungen von J. A. Hartung. Leipzig, 1850.

${ }^{11}$ CAMPIONI, G. (Org.). Nietzsches persönliche Bibliothek. p. 98-106. 
Sophokles. König Oedipus. Griechisch mit metrischer Uebersetzung und prüfenden und erklärenden Anmerkungen von J. A. Hartung. Leipzig, W. Engelmann, 1851.

Sophokles. Sophokles. Erklaert von F. W. Schneidewin. Dritte Auflage. Berlin: Weidmann, 1855. [I. Bd.: Aias, Philoctetes].

Sophokles. Sophokles. Erklärt von F. W. Schneidewin. 2 Bde. 3. Aufl. Berlin: 1855, 1856. [I. Bd.: Aias, Pbiloctetes; II. Bd.: Oedipus Tyrannos].

Sophokles. Sophokles. Erklaert von F. W. Schneidewin. Dritte Auflage. Berlin: Weidmann, 1856. [Zweites Baendchen: Oedipus Tyrannus].

Sophokles. Tragoediae. Edidit Theodorus Bergk. Editio Stereotypa. Lipsiae: B. Tauchnitz, 1858.

Sophokles. Oedipus tyrannus. In usum scholarum edidit Mauricius Schmidt, Ienae: H. Dufft (in Libraria Maukiana), $1871 .{ }^{12}$

Exceto em relação ao filólogo J. A. Hartung, estudioso que é também autor, por exemplo, da obra Ungelebrte Erklärung des Goethe'schen Faust (1845), percebe-se que, no que diz respeito aos textos de Sófocles, Nietzsche buscou as edições estabelecidas por Christian Grafen zu Stolberg (Christian Stolberg, 1748-1821), F. W. Schneidewin (Friedrich Wilhelm Schneidewin, 1810-1856), Theodorus Bergk (Theodor Bergk, 1812-1881) e Mauricius Schmidt (Moritz Schmidt, 1823-1888).

Por fim, vejamos os textos de Eurípedes. Do "trágico grego" criticado no Nascimento da tragédia como aquele que "confessava a si mesmo que não conhecia seus grandes predecessores [Ésquilo e Sófocles]” (GT/NT, \11), Nietzsche possuía em sua biblioteca pessoal os seguintes exemplares:

Euripides. Tragoediae sex, Medea, Hippolytus, Alcestis, Hecuba, Phoenissae, Orestes. Oxonii et Londini: Parker, 1848.

Euripides. Trojerinenn. Griechisch mit metrischer Uebersetzung und prüfenden und erklärenden Anmerkungen von J. A. Hartung. Leipzig: W. Engelmann, 1848.

Euripides. Medea. Griechisch mit metrischer Uebersetzung und prüfenden und erklärenden Anmerkungen von J. A. Hartung. Leipzig: W. Engelmann, 1848.

Euripides. Werke. Griechisch mit metrischer Übersetzung und prüfenden und erklärenden Anmerkungen von J. A. Hartung. II. - V., VI. u IX. Bändchen [in 3 Bde geb.].

12 CAMPIONI, G. (Org.). Nietzsches persönliche Bibliothek. p. 560-565.

50 fragmentum, N. 38, Vol. 1. Laboratório Corpus: UFSM, Jul./ Set. 2013 
Leipzig: W. Engelmann, 1848-50. [Bändchen: II, Trojerinnen; III, Hippolyt, IV, Orestes; V, Phönikerinnen; VI, Rasender Herakles; IX, Jon).

Euripides. Orestes. Griechisch mit metrischer Uebersetzung und prüfenden und erklärenden Anmerkungen von J. A. Hartung. Leipzig: W. Engelmann, 1849.

Euripides. Pbönikerinnen. Griechisch mit metrischer Uebersetzung und prüfenden und erklärenden Anmerkungen von J. A. Hartung. Leipzig: Engelmann, 1849. Euripides’ Werke.

Euripides. Rasender Herakles. Griechisch mit metrischer Uebersetzung und prüfenden und erklärenden Anmerkungen von J. A. Hartung. Leipzig: W. Engelmann, 1849.

Euripides. Bakchen. Griechisch mit metrischer Uebersetzung und prüfenden und erklärenden Anmerkungen von J. A. Hartung. Leipzig: W. Engelmann, 1849.

Euripides. Jon. Griechisch mit metrischer Uebersetzung und prüfenden und erklärenden Anmerkungen von J. A. Hartung. Leipzig: W. Engelmann, 1850.

Euripides. Alkestis. Griechisch mit metrischer Uebersetzung und prüfenden und erklärenden Anmerkungen von J. A. Hartung. Leipzig: W. Engelmann, 1850.

Euripides. Iphigenia in Tauris. Griechisch mit metrischer Uebersetzung und prüfenden und erklärenden Anmerkungen von J. A. Hartung. Leipzig: W. Engelmann, 1852.

Euripides. Euripidis Tragoediae ex recensione Augusti Nauckii. Editio Altera. Volumen II, Lipsiae: B. G. Teubner, 1860.

Idem. Volumen II, Lipsiae: B. G. Teubner, 1866.

Euripides. Hekabe. Tragödie des Euripides. In das Deutsche übertragen von F. Tiro. Leipzig: Reclam, o. J. [1879?]. ${ }^{13}$

Grosso modo, as edições de Eurípedes investigadas por Nietzsche foram editadas entre os anos de 1848 e 1866, com exceção de uma, provavelmente publicada em 1879. Em sua maioria, os textos gregos estão estabelecidos J. A. Hartung e compõem a sua "Euripides' Werke". Comparece aqui também outro filólogo alemão, Augusti Nauckii (August Nauck, 18221892), autor, entre outros, do Euripideische Studien (Petersburg 1859-62, 2 T.), e ainda F. Tiro (sobre o qual não há referências biográficas e bibliográficas), autor da última edição sobre Eurípedes adquirida por Nietzsche.

${ }^{13}$ CAMPIONI, G. (Org.). Nietzsches persönliche Bibliothek. p. 219-223. 
Com base nestas informações, muitas são as questões de pesquisa que poderíamos levantar, tais como: de que modo foi estabelecida cada edição? $\mathrm{O}$ que o filósofo anotou em cada uma delas? Quais obras ele leu e em que períodos? Teve contato com a bibliografia produzida pelos filólogos e helenistas cujas edições ele adquiriu? Que influência os prefácios e notas críticas tiveram sobre Nietzsche? De todo modo, para bem compreender as teses nietzschianas em andamento, por exemplo, no Nascimento da tragédia, caberia ainda investigar os estudos críticos e interpretações dos trágicos gregos, tais como aquelas que ele mesmo menciona em sua primeira obra, entre eles Aristóteles, Schiller, Schlegel.

Publicada há dez anos, certamente a Nietz̧sches persönliche Bibliothek já forneceu novas pesquisas (por exemplo, no estudo de Nietzsche dos trágicos gregos). Caberia, neste sentido, antes de arriscar hipóteses, realizar novos levantamentos bibliográficos para ver que temas já foram desenvolvidos e o modo como isto foi feito a partir do trato com estas fontes. De todo o modo, o recente anúncio de que em junho de 2014 ocorrerá o VII Congresso do Grupo International de Recherche Nietzsche (GIRN), cujo tema é "Nietzsche. Os primeiros textos sobre os gregos", já indica que ainda restam novas pesquisas para serem exploradas neste manancial.

Recebido em 28 de Junho de 2013. Aceito em 17 de Agosto de 2013. 


\section{REFERÊNCIAS}

MACHADO, Roberto. Nietzssche e a polêmica sobre o Nascimento da tragédia. Rio de Janeiro: Editora Zahar, 2005.

NIETZSCHE, Friedrich. Sämtliche Werke. Kritische Studienausgabe. Edição organizada por Giorgio Colli e Mazzino Montinari,. Berlim/Munique, Walter de Gruyter \& Co., 1967-78. 15 vol.

Sämtliche Briefe. Kritische Studienausgabe em 8 volumes, Berlim/Munique, Walter de Gruyter \& Co./DTV, 1986.

. Obras Incompletas. Col. "Os Pensadores". Seleção de textos de Gerárd Lebrun; tradução e notas de Rubens Rodrigues Torres Filho. Col. "Os Pensadores". $4^{a}$ ed. - São Paulo: Nova cultural, 1987. . Nietzsche persönliche Bibliothek. Herausgegeben von Giuliano Campioni, Paolo D'Iorio, Maria Cristina Fornari, Francesco Fronterotta und Andrea Orsucci. Berlin-New York: Walter de Gruyter, 2003.

O nascimento da tragédia on Helenismo e pessimismo. Tradução, notas e posfácio J. Guinsburg. São Paulo: Companhia das Letras, 1992. . Ecce homo. Tradução Paulo César de Souza. São Paulo: Companhia das Letras, 1995. 